Caligrama, Belo Horizonte, v. 26, n. 3, p. 127-136, 2021

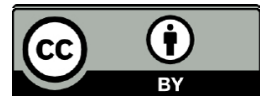

\title{
Elipses da memória: entre o leitor e o escritor (Entrevista com Michel Laub) ${ }^{1}$
}

\author{
Marcio Roberto Pereira \\ Universidade Estadual Paulista Júlio de Mesquita Filho (UNESP), Assis, SP/Brasil \\ marcio.pereira@unesp.br \\ http://orcid.org/0000-0003-4311-9629 \\ Ana Paula Vicente Carneiro \\ Universidade Estadual Paulista Júlio de Mesquita Filho (UNESP), Assis, São Paulo/ \\ Brasil \\ anap.vic.carneiro@gmail.com \\ http://orcid.org/0000-0001-7335-1301
}

Nascido em Porto Alegre em 1973, atualmente Michel Laub reside na cidade de São Paulo. Sendo escritor e jornalista, atua como colunista no Valor Econômico, além de colaborar com diversas editoras e veículos, escrevendo seus romances entre um e outro trabalho entregue. Ademais, fez parte da revista Bravo! como editor-chefe, foi coordenador de publicações e internet do Instituto Moreira Salles e colunista da Folha de S. Paulo e do Globo.

Autor de um livro de contos - Não depois do que aconteceu (1998) - e oito romances - Música anterior (2001), Longe da água (2004), O segundo tempo (2006), O gato diz adeus (2009), Diário da queda (2011), A maçã envenenada (2013), O tribunal da quinta-feira (2016) e Solução de dois estados (2020) -, com uma considerável lista de prêmios literários no Brasil e no exterior, é perceptível nos escritos de Laub um viés trágico com tendências memorialísticas. $\mathrm{O}$ próprio autor, antes mesmo da publicação de $A$ maçã envenenada, anunciou-o junto a

1 Entrevista feita pela pesquisadora Fapesp Ana Paula Vicente Carneiro, via aplicativo de comunicação virtual Whatsapp, no dia 10 de março de 2021. 
Diário da queda e seu sucessor, $O$ tribunal da quinta-feira, como uma Tríade de Tragédias Históricas, reforçando o caráter crítico e caótico da ótica pela qual seus narradores observarão os próprios problemas em contraste com o mundo que os cerca.

Mesmo que nem tudo tenha relação direta com a realidade do autor, Laub afirma que a escrita é a sua forma de digerir o mundo; através de seus romances, ele transforma tudo o que foi experenciado por ele, direta ou indiretamente, em literatura. Em um mundo globalizado, com as fronteiras fragilizadas pela tecnologia, que serve como veículo de notícias em um constantemente bombardeio de tragédias diversas, Laub reconhece em si essa necessidade quase terapêutica de valer-se da arte para se expressar. Em sua tríade, especificamente, é possível observar até mesmo certa obsessão de seus narradores autodiegéticos por eventos passados, em uma tentativa de atualizá-los e conectá-los de alguma forma com o presente. É como se as experiências fossem se acumulando ao longo dos anos sem que os narradores se dessem conta disso, até que um dia, um único acontecimento seja capaz de torná-los conscientes do peso das palavras não ditas; a literatura, no caso, é o veículo escolhido por tais vozes.

O projeto de Iniciação Científica "Tríade de tragédias históricas: literatura de testemunho e formação em Michel Laub", financiado pela FAPESP, busca, dentre outras coisas, analisar o uso estilístico do hibridismo de gênero nos romances de Laub, investigando a recorrência da reescrita da memória traumática em diálogo com o presente. Portanto, a presente entrevista é parte de tal de projeto, com enfoque não apenas em questões norteadoras envolvendo a tríade literária, mas também na figura do autor, tão lida nas entrelinhas dos romances de Laub.

Ana Paula Vicente Carneiro: Fale um pouco sobre a sua experiência enquanto leitor. O que você lia na infância?

Michel Laub: Na infância, eu comecei lendo gibis. Eu aprendi a ler com os gibis, na verdade, antes mesmo de aprender no colégio. Depois, passei para os livros infanto-juvenis que eram populares na época, Coleção Vaga-Lume, Para Gostar de Ler, coisas assim. Acredito que cada uma dessas fases tenha sido um ganho, de certa forma, pois primeiro você começa com livros infantis sem texto, depois imagem e texto, e aí livros infanto-juvenis ainda com imagem e texto, porém mais texto do que imagens. Depois, fui conquistando a autonomia da leitura 
até chegar lá pelos quinze, dezesseis anos - idade na qual considero que comecei a ler de verdade - quando os livros que eu lia eram mais adultos, por assim dizer.

Me lembro de que algumas coisas me marcaram nessa trajetória de leitura. Por exemplo, Os meninos da rua Paulo, de Ferenc Molnár, que eu li ali pelos doze, treze anos - esse foi um dos daqueles livros que tinham mais texto do que imagem, assim, que a imagem não era tão importante. $\mathrm{Na}$ adolescência, mesmo, eu li muito Agatha Christie; durante uns dois ou três anos, eu li muita coisa da Agatha Christie. Devo ter lido uns vinte livros dela. Foi a época que eu peguei mais gosto, talvez, pela leitura.

Houve também um período de transição, lá pelos quinze ou dezesseis anos, quando eu li O nome da rosa, do Umberto Eco, que era um romance policial também, mas com referências mais eruditas, mais densas; a partir daí, acredito que eu tenha começado a criar aquele fôlego, aquela resistência, que precisa ter para ler um livro com um pouco mais de complexidade - que são os livros da vida adulta. Então, acredito que eu tinha um esquema de leitura tradicional, por assim dizer, bem próximo ao das pessoas da minha idade, com certas particularidades, claro, que você acaba desenvolvendo.

Carneiro: E hoje, quais são as suas preferências de leitura?

Laub: Hoje em dia, eu leio muito por trabalho. Faz umas duas décadas já que eu trabalho na imprensa, inclusive escrevendo a respeito do que leio. E sendo um escritor contemporâneo, eu gosto de ler contemporâneos, brasileiros e estrangeiros. Nem sempre eu gosto do que leio, mas é um tipo de leitura do qual preciso, até para saber o que se está produzindo no mundo hoje em dia. Por exemplo, tem uma coluna lá no Valor Econômico que a cada duas semanas eu preciso escrever duas páginas, sempre sobre algum livro - de preferência, lançamento e às vezes eu faço sobre mais de um livro. Então essa leitura acaba me consumindo bastante tempo. Mas claro que eu reservo um pouco do meu tempo - uns 30\%, talvez - para essa leitura que de fato gosto.

Estamos falando de épocas diferentes quando o assunto é gostar de um e de outro autor, mas constantemente - digamos, assim, nos últimos dez anos - posso citar o Coetzee, escritor sul-africano, o Thomas Bernhard - inclusive, acabei por ler todas as suas obras. Alguns autores desse tipo eu gosto de acompanhar, por assim dizer. No Brasil, durante muito tempo, acompanhei a produção do Rubem Fonseca - acredito 
que até os anos 90 eu o li - também o Caio Fernando de Abreu, o João Gilberto Noll, esses autores que fazem o tipo dos leitores adolescentes no início da juventude. Então, na vida adulta, são esses os quais citei, além de muitos romancistas americanos, tais como William Faulkner, os escritores de New Journalism, o Philip Roth, enfim, são minhas referências dos últimos vinte anos, pelo menos.

Sobre os últimos três ou quatro anos, posso citar Lucia Berlin - da qual gostei muito - e os ensaios da Susan Sontag. Comecei a reler Nelson Rodrigues, inclusive, e o Thomas Mann. Acredito que os nomes aqui citados sirvam de referência para o que venho fazendo nos últimos anos.

Carneiro: Sobre seu processo criativo, você acredita que a história toma rumos que fogem ao controle do escritor? Ou você, geralmente, consegue elaborar um roteiro e ser relativamente fiel a ele?

Laub: Sim, acredito que a história toma seus próprios rumos, pois é uma questão de linguagem mesmo. Você começa a escrever sempre testando perspectiva, narrador, o tom - inclusive, estou tentando escrever algo novo. Algumas coisas dão certo, outras não, de acordo com o que você está tentando fazer naquele dia. E às vezes tem o acaso mesmo, seu humor e seu estado de espírito, acabam interferindo no processo criativo.

Às vezes, por exemplo, você tenta escrever em terceira pessoa, mas não dá certo, e você muda para a primeira, então. Isso acaba interferindo em outras escolhas que você deve fazer enquanto escritor, pois algumas coisas são possíveis na narrativa em terceira pessoa, mas não em primeira. Acredito que isso muda totalmente a história, pois ela acontece através da perspectiva de quem está narrando; a forma escolhida para contar uma história, geralmente é um forte indicativo de como essa história será. E isso é, de fato, um processo muito ao acaso. O livro tem 150,200 páginas, cada parágrafo possivelmente foi algo que surgiu do nada. Às vezes, é algo que você ouviu na rua e que acaba tendo o ímpeto de usar no texto, às vezes a escolha lexical acaba te conduzindo a uma série de coisas inesperadas.

Sobre elaborar roteiros, nunca consegui. Geralmente eu vou pensando e escrevendo - o que acaba por ser uma grande dificuldade, na verdade, pois eu adoraria ter as coisas mais planejadas, mas infelizmente para mim nunca funcionou assim. Então, às vezes, acabo demorando muito mais tempo para escrever algo do que em um primeiro momento acreditei que demoraria. Meus livros são sempre relativamente curtos, 
mas, por exemplo, esse último - Solução de dois estados - demorei quase quatro anos para escrever. E é um livro relativamente simples, a um primeiro olhar, mas acredito que possivelmente tenha sido meu livro mais difícil de ser escrito, pois perdi muito tempo para chegar na simplicidade daquelas entrevistas nele narradas.

Mas acho que isso faz parte do processo, você vai escrevendo eu, no caso, já tenho oito livros lançados - e percebe que isso é parte do processo, não adianta se queixar. Agora que estou tentando algo novo, estou patinando no vazio, e isso vai se estender por meses até que acontece aquele clique, que te dá pelo menos o tom do livro, a perspectiva do narrador etc. e a partir daí as coisas se tornam um pouco mais fáceis. Então essa questão do roteiro, o mais próximo disso seria justamente esse processo, esses meses de preparação acabam sendo uma espécie de roteiro mental. Você vai descartando coisas que sabe que não vão funcionar e vai ficando mais fácil pensar a história a partir de menos elementos, e não a partir da infinita possibilidade de elementos que você tem no início de um romance.

Carneiro: Ainda sobre seu processo de escrita, o que mais te inspira a escrever? Você tem uma rotina exclusiva para tanto ou responde a eventuais periodos de criatividade?

Laub: Quando escrevo ficção, não trabalho sob encomenda. Não sei o que seria inspiração, exatamente, mas o que tenho notado é que ao longo dos últimos vinte anos a escrita tem se tornando parte da minha vida. Eu me sinto muito bem, poderia dizer que até aliviado, quando vejo um livro finalizado, mas depois de uns seis meses, mais ou menos, sinto essa angústia que me leva a escrever de novo. Então acredito que escrever acabou sendo algo que responde a uma demanda da minha própria vida, de ansiedades minhas, de sempre ter um projeto em curso, enfim, coisas que me ajudam a viver o dia a dia - uma forma de escapar, talvez, acreditando que sempre exista algo maior acontecendo em minha vida, pois se tudo der errado nas outras áreas, até mesmo no trabalho, eu sempre terei algo a fazer.

E não é algo utilitário, é uma coisa existencial mesmo. Quando se está escrevendo um livro, tem um processo muito legal que é uma quase autoanálise ao longo do período de escrita; você vai pensando sobre o mundo, sobre você mesmo, e isso acaba aparecendo no livro de algum jeito. Nos primeiros livros, eu tinha mais pressa de terminar, para que 
o livro fosse publicado logo, mas hoje eu acredito entender melhor o processo. É bom, inclusive, que demore, pois eu vou incorporando coisas da minha vida dentro daquela história. Mesmo que aparentemente tais coisas não tenham nada a ver com as minhas experiências, é uma maneira de lidar com os problemas, é quase uma sessão de análise ali, que está sob a forma de um livro de ficção. E quando o livro termina, parece que eu consegui colocar para fora coisas que eu penso, principalmente sobre o tema do livro. Esse último [romance], que fala muito sobre o Brasil, é algo sobre o qual eu penso todos os dias, assim como todo mundo - o que aconteceu, nos últimos anos, com o nosso país nos obriga a isso - e, para mim, foi um processo terapêutico escrevê-lo. Não que eu o tenha preenchido com minhas opiniões, não, mas a forma de pensar no país, e colocar isso em uma trama, acabou me fazendo muito bem nesse período tão difícil - inclusive, um período que acabou por abranger a pandemia, já que eu o terminei [o livro] em meados de maio de 2020.

Carneiro: Escrever é um processo trabalhoso, sabemos disso. Demanda tempo, inspiração, paciência, perseverança, dentre tantos outros atributos. Então, por que escrever?

Laub: Sobre isso, eu não tenho a resposta, realmente. Eu poderia responder de mil jeitos, inclusive de formas românticas, sobre a necessidade de expressão - que eu acredito até existir. É uma mistura de necessidade de expressão com a vontade de ser gostado, de alguma maneira, que leiam o que você escreve, enfim, uma pretensão de acreditar que os outros irão se interessar pelo que você tem a dizer. Tem tudo isso, mas eu não sei. Às vezes, uma coisa anula a outra, então, no fundo, talvez a resposta mais honesta tenha a ver com aquilo que falei antes, algo sobre minha própria vida. Ter sempre um projeto é algo que me mantém em movimento.

Eu nunca tive depressão, por exemplo - claro que tenho episódios de melancolia, tal como todo mundo hoje em dia, aqueles momentos nos quais se fica em estado de total prostração - mas o livro ajuda a seguir em frente. É um estímulo, portanto, que é existencial e que não tem apenas a ver com o livro, tem a ver com a sua vida: acordar de manhã, tomar um café, pensar que você vai trabalhar naquele dia e que isso seja um prazer, pois muitas vezes não é. E quando você consegue fazer uma boa sessão, se sentindo satisfeito com aquilo que foi escrito, isso causa uma grande sensação de prazer que ajuda, de fato, a manter o humor 
em uma frequência agradável. Isso acaba, por tabela, ajudando a manter as demais coisas da vida, os compromissos de um modo geral, sua vida afetiva, inclusive, pois você não está caindo ali em um espiral de niilismo e tristeza, ou seja lá o que for.

Carneiro: Certa vez, você disse que nunca sonhou em ser escritor, que isso simplesmente aconteceu. Você acredita que algo nessa experiência tenha alimentado sua vontade de escrever, apesar das dificuldades em ser escritor em um país onde as pessoas leem cada vez menos?

Laub: De fato, nunca pensei, quando criança ou adolescente, em ser escritor nesse sentido de ser romancista. Eu gostava de escrever, fazia umas revistinhas em casa. Talvez eu tenha pensado em ser jornalista, não sei se na época nesses termos, mas eu gostava dessa ideia, a imprensa jornais, revistas - me interessavam muito. Isso falando dos anos oitenta. E tinha uma pretensão aí, até tem um pouco a ver, eu queria sim ser músico, ter uma banda, queria cantar e essas coisas, e acho que ambas as coisas acabaram se juntando em algum momento nessa necessidade de expressão pessoal, meio artística talvez, que através da música acabou não dando certo - acho que eu não tinha nem talento e nem disposição para isso, sei lá - mas acabei canalizando isso para outro instrumento.

Então, em lugar da música, a escrita, que eu já dominava um pouco melhor - pelo menos, acho que sou melhor nisso do que eu seria como músico - então ambas as coisas casaram e eu acabei virando escritor. Mas eu não acho que seja a forma da escrita que me interesse tanto - ou que tenha me interessado, de fato, no passado - e mais essa questão da expressão pessoal. Então, dá para dizer que, de algum modo, isso estava lá atrás, o que eu não pensei é na figura do escritor. Até porque, na época, eu não tinha nem ideia, não conhecia nenhum escritor, pois não vim de um meio intelectual onde meus pais seriam amigos de escritores, de gente da cultura, nada disso. Meu pai era engenheiro, minha mãe era professora, por isso tínhamos livros em casa, mas não éramos uma família assim, de perfil de alta intelectualidade, então eu não tinha nem esse modelo [de escritor] para me basear. Então eu acabei indo para um modelo que estava mais próximo da minha vida, dos meus colegas de colégio, que era esse da música, das bandas de rock etc.

E sobre isso de ser escritor em um país onde as pessoas leem cada vez menos, acho que você não pensa nisso quando se está começando. 
É um misto de altíssima ambição - até por ignorância, de achar que as coisas podem dar super certo - com o pensamento, que não está voltado para o lado utilitário da coisa, mas sim em estar fazendo algo que você gosta. Ao menos, acredito que era assim que eu pensava quando comecei, que eu estava fazendo algo que gostava, algo que eu fazia com alguma naturalidade, e aí esse abismo do país que não lê você vai percebendo até mais quando você escreve. Antes, claro que eu sabia das estatísticas, mas eu gostava de ler e tinha amigos que gostavam de ler. Eu lia os livros do Rubem Fonseca e eu não imaginava que ele fizesse algo além de escrever os livros que eu lia - no caso dele, ele até conseguiria viver de escrita, mas o Caio Fernando de Abreu, que eu também lia muito, certamente não vivia dos livros dele; mas eu, quando lia, imaginava que sim.

Então, você tem uma certa ingenuidade, lá atrás, que até impede que você pese essas coisas com os elementos de avaliação que você tem hoje, pois uma vez que você entra no meio literário, é uma profissão que você escolheu e com ela você vai até o fim. Tal como o jornalista, que hoje enfrenta uma situação muito precária no país - pois a imprensa está acabando, de certo modo - então essa pessoa tem um dilema muito maior do que o escritor. Acredito que toda profissão esteja sujeita a isso, a qualquer momento a tecnologia pode substitui-la, e não acredito que isso irá influenciar ninguém definitivamente no início da carreira, caso a pessoa tenha alguma vocação. E quando você tem a vocação, você sabe um pouco e, não sei se eu tinha exatamente essa vocação para escritor, mas sempre senti essa necessidade de me expressar de uma forma artística, e o instrumento escolhido acabou sendo a escrita ficcional.

E também o trabalho solitário da escrita, diferente da música e do cinema, por exemplo, é uma sorte, pois hoje eu lamento muito pelos meus amigos cineastas ou músicos - que com a pandemia, não tem muitas opções de para onde ir ou o que fazer - pois eles estão em uma situação muito pior. Escritor, então, é mais simples, pois você consegue se sentar e fazer suas coisas. Mesmo com tudo o que está acontecendo, pois ainda que sejam poucos os leitores, existe um público que se interessa pelo que a gente faz e isso acaba sendo um estímulo.

Carneiro: Quando surgiu a ideia de reunir Diário da Queda (2011), A maçã envenenada (2013) e O tribunal da quinta-feira (2016) em uma tríade? 
Laub: Acredito que tenha sido durante a escrita de $A$ maçã envenenada, quando percebi que tinha essa possível ligação - você que conhece os textos deve saber qual é - e eu já tinha uma ideia de escrever algo sobre a epidemia de AIDS e me pareceu que as três coisas - Auschwitz, o massacre de Ruanda e a AIDS - eram três coisas que poderiam ser relacionadas.

Eu não sei se foi um acerto ou um erro, talvez tenha sido até mesmo um erro ter anunciado isso como uma trilogia já no segundo livro, pois se criou uma expectativa em relação ao terceiro e se criou uma comparação até mesmo injusta entre $A$ maçã envenenada e o Diário da queda. O Diário da queda tem mais a ver com meu universo, enquanto A maçã envenenada é um livro até mesmo um pouco mais frio, por assim dizer, que fala sobre uma coisa um pouco mais distante - que seria sobre o massacre de Ruanda - o que acabou por prejudicar, na época, a recepção do livro.

Mas enfim, foi o que foi, eu poderia ter escrito os três textos sem chamá-los de trilogia e deixar que as outras pessoas os enxerguem ou não como uma trilogia. Acredito que será isso o que farei daqui para a frente, pois volta e meia eu lanço algo e, por exemplo, Solução de dois estados poderia muito bem estar em uma trilogia com $O$ tribunal da quinta-feira, talvez até com maior proximidade do que esses outros dois, mas eu acho que esses conceitos devem ser deixados para a crítica. Você, que está fazendo esses estudos, se quer chamar assim também, ótimo, pois é uma interpretação de alguém de fora que tem mais elementos do que eu - já que enquanto escritor eu estou muito envolvido - e quando eu vejo essa questão de rotular a própria obra, que é uma coisa que todo autor faz, percebo que estes devem ser dados pelos leitores, por estudiosos, por gente que lê muito tempo depois e que nem te conhece etc.

Carneiro: Com a publicação de $\mathrm{O}$ tribunal da quinta-feira, você afirmou finalizar uma tríade de romances de formação. O que diferencia, em sua opinião, Solução de dois estados (2020), seu romance mais recente, dos três anteriores?

Laub: Acredito que eu já tenha respondido um pouco dessa pergunta na anterior, mas retomo que existe muito em comum entre Solução de dois estados e O tribunal da quinta-feira. Não apenas isso, existe muito em comum entre esse meu último romance e os demais já publicados, afinal, sou eu escrevendo, mas também tem coisas muito 
diferentes - tais como os livros da trilogia têm muitas coisas diferentes entre si. O livro Solução de dois estados, acredito, tal como falei lá na primeira questão, tem algo sobre a forma dele que acaba determinando muito o tipo de história que eu estou contando, o tipo de tema que eu desenvolvo. Como esse livro tem mais de um narrador - são três em primeira pessoa - e são todos com um ponto de vista subjetivo muito radical, a minha opinião enquanto autor sobre todos aqueles temas ali ela acaba muito mais diluída ao longo do livro. Então, acredito que ele seja mais complexo nesse sentido, pois para entender o que eu tenho a dizer sobre o Brasil em um contexto atual precisa ler os três pontos de vista, formando na cabeça do leitor uma síntese daquilo - um trabalho mais subjetivo, mais complexo do que os anteriores, creio eu.

Nesse sentido, vejo uma certa evolução em relação aos outros livros, e foi algo que gostei bastante de fazer. Não sei se continuarei fazendo, pois cada livro tem seus desafios, mas no caso desse foi justamente o que aconteceu. Eu queria dar voz para pessoas que pensam não necessariamente como eu penso e, a partir do cruzamento dessas vozes, talvez, exista uma síntese, não digo do que eu penso, pois para mim o livro é mais uma composição de uma série de perguntas que eu faço a mim mesmo do que de uma resposta única.

Carneiro: Muito obrigada, Laub, pelo seu tempo e atenção, além da gentileza e paciência em responder nossas perguntas.

Recebido em: 12 de abril de 2021.

Aprovado em: $1^{\circ}$ de maio de 2021. 